NBER WORKING PAPER SERIES

\title{
MONETARY DISCRETION, PRICING COMPLEMENTARITY AND DYNAMIC MULTIPLE EQUILIBRIA
}

\author{
Robert G. King \\ Alexander L. Wolman \\ Working Paper 9929 \\ http://www.nber.org/papers/w9929
NATIONAL BUREAU OF ECONOMIC RESEARCH
1050 Massachusetts Avenue
Cambridge, MA 02138 \\ August 2003
}

This paper is an outgrowth of the authors' work in progress with Aubhik Khan, available at http://www.rich.frb.org/pubs/wpapers/pdfs/wp01-8.pdf; it does not necessarily represent the views of the Federal Reserve System, the Federal Reserve Board, or the Federal Reserve Bank of Richmond. We have benefited from conversations with Russell Cooper, Huberto Ennis, Andreas Hornstein, John Leahy and Henry Siu, and from presentations at Harvard, Iowa, MIT, the New York Fed, UQAM, Western Ontario, Wharton, York, and the conference on Dynamic Models at the Bank of Canada, July 2003. The views expressed herein are those of the authors and not necessarily those of the National Bureau of Economic Research.

(C)2003 by Robert G. King and Alexander L. Wolman. All rights reserved. Short sections of text, not to exceed two paragraphs, may be quoted without explicit permission provided that full credit, including (C) notice, is given to the source. 
Monetary Discretion, Pricing Complementarity and Dynamic Multiple Equilibria

Robert G. King and Alexander L. Wolman

NBER Working Paper No. 9929

August 2003

JEL No. E5, E61, D78

\begin{abstract}
In a plain-vanilla New Keynesian model with two-period staggered price-setting, discretionary monetary policy leads to multiple equilibria. Complementarity between the pricing decisions of forward-looking firms underlies the multiplicity, which is intrinsically dynamic in nature. At each point in time, the discretionary monetary authority optimally accommodates the level of predetermined prices when setting the money supply because it is concerned solely about real activity. Hence, if other firms set a high price in the current period, an individual firm will optimally choose a high price because it knows that the monetary authority next period will accommodate with a high money supply. Under commitment, the mechanism generating complementarity is absent: the monetary authority commits not to respond to future predetermined prices.

We compute a traditional inflation bias equilibrium, in which price-setters are optimistic, rationally expecting small adjustments by other firms. But there is another steady-state equilibrium in which price setters are pessimistic and inflation is much higher. Further, we find that there are multiple equilibria at a point in time, not just in steady states. In a stochastic setting with equilibrium selection each period determined by an i.i.d. sunspot, there is greater inflation bias on average than if price-setters were always optimistic. The sunspot realization also has real effects: periods of higher than average inflation are accompanied by low output. Thus, increased real volatility may be an additional cost of discretion in monetary policy.
\end{abstract}

Robert G. King

Department of Economics

Boston University

270 Bay State Road

Boston, MA 02215

and NBER

rking@bu.edu
Alexander L. Wolman

Research Department

Federal Reserve Bank of Richmond

701 East Byrd Street

Richmond, VA 23219

Alexander.Wolman@rich.frb.org 


\section{Introduction}

In the debate over rules versus discretion for monetary policy, the primary argument against discretion has been that it leads to a higher average inflation than is optimal with commitment. In the consensus basic model which has developed following Kydland and Prescott [1977] and Barro and Gordon [1983], the discretionary monetary authority seeks to produce unexpected inflation to stimulate real output, which is inefficiently low because of distortions in the economy. But since it cannot fool agents in rational expectations equilibrium, the discretionary monetary authority produces expected inflation that has a negligible real effect on output, while imposing other costs on the economy.

By contrast, this paper provides an example of a different, potentially adverse, consequence of discretionary monetary policy: it can lead to multiple equilibria and, thus, to the possibility of endogenous fluctuations in inflation and real activity that are not related to the economy's fundamentals. We illustrate this possibility within a simple dynamic macroeconomic model that has important New Keynesian features: (i) monopolistic competition, making output inefficiently low; and (ii) a staggered pricing structure in which firms set nominal prices that must be held fixed for two periods. These two features give the monetary authority some leverage over real activity.

In this simple setting, the multiplicity of equilibria derives from interaction between two features of the economy. First, firms adopt forward-looking pricing rules because their nominal prices are held fixed for two periods. In choosing a price, firms in the current period need to form expectations about the behavior of the monetary authority - and firms - in the next period. A higher future money supply leads to a higher future nominal marginal cost, which raises the optimal price for a firm in the current period. Second, under discretion, the monetary authority takes as given prices set in previous periods in determining its choice of the money stock in each period. Since its concern is to maximize the welfare of the representative agent, which depends on real variables, it chooses a money stock that is proportional to the price set by firms in the previous period, which we call a homogenous money stock rule.

The combination of forward-looking pricing with discretionary policy leads to complementarity between the price-setting actions of firms: if all other firms set a higher price in the current period, the monetary authority will set a higher money supply in the subsequent period, raising the desired price for a single firm in the current period.

We show that this policy-induced complementarity implies that there are typically two private-sector equilibria which can prevail at any point in time and two steadystate equilibria. In general, there is one equilibrium in which firms expect small adjustments and the newly set price is relatively close to the price that firms set

last period. But there is another in which the adjusting firms make a much larger adjustment. 
Because this multiplicity of equilibria arises for arbitrary homogenous monetary policies, it also arises with an optimizing monetary authority who cannot commit to future actions. We begin by considering settings of perfect foresight, in which the monetary authority and private agents each assume that only one of the two types of private sector equilibria will occur. We show that there are two steadystate discretionary equilibria, one with low inflation bias and one with high inflation bias. It is notable that the complementarity which generates multiple equilibria is entirely due, in our model, to the nature of monetary policy under discretion. That is: our specification of preferences and the labor market is such that there is no complementarity in the price-setting behavior of firms if the central bank maintains a fixed nominal money stock. Our setup thus highlights the role of discretionary monetary policy in generating complementarity.

There are three components of the existing literature to which our paper relates. First, there is the voluminous literature on monetary policy under discretion, which begins with Kydland and Prescott [1977] and Barro and Gordon [1983]. In that literature, output is inefficiently low, but can be raised by policies that also produce unexpected inflation. There are costs of actual inflation, so that a consistent equilibrium exhibits an inflation bias. The model that captures these ideas involves a quadratic monetary authority objective and a linear economic model. There is a unique discretionary equilibrium in the standard model (absent reputational effects or trigger strategies).

Second, there is an important recent literature that works out how the standard KPBG model can be derived from a fully articulated New Keynesian framework. The key ingredients of the models in this literature are that output is inefficiently low due to monopoly distortions; the monetary authority has temporary leverage over the real economy because of staggered price setting; and the costs of actual inflation are welfare losses associated with relative price distortions. In these settings, just as in the KPBG model, there is an inflation bias under discretion. ${ }^{1}$ However, this analysis has been conducted within linearized versions of modern sticky price models.

Our analysis takes the most basic fully articulated New Keynesian model, without linearizing, and shows that there are multiple equilibria. Our model features costs of stimulative policies - which bring about actual inflation - that stem from relative price distortions across goods. It also features benefits from unexpected stimulative policies, which lower monopoly markups and raise output toward the first best level. Our model is an explicitly dynamic one, with firms forecasting future inflation when setting nominal prices for two periods. As we have stressed above, multiple equilibria can occur in our model due to complementarity mechanisms similar to those stressed in the literature on coordination failures. The possibility of such responses is excluded by a model that is linear.

\footnotetext{
${ }^{1}$ For a textbook treatment, see the derivation in Woodford [2002, chapter 3]. The inflation bias result under discretion within such optimizing New Keynesian models has been popularized by Clarida, Gali and Gertler [1999].
} 
Third, our paper is closely related to recent work by Albanesi, Chari and Christiano [2002]. They find multiple equilibria in an essentially static model where a portion of monopolistically competitive firms must set prices before the monetary authority's action in each period. At the same time, the structure of the model they study is quite different from ours. The stimulative policies that produce inflation in their model also raise nominal interest rates and lead to money demand distortions, either by driving a relative price wedge between the cost of buying goods on cash and credit or by increasing transactions time. A monetary authority thus faces a trade-off between the benefits of driving down the markup and these costs. In our model, instead of the costs of realized inflation being related to money demand, they involve price distortions across goods whose prices were set in different periods.

If there are sunspots which switch the economy between equilibria, there are also important differences in the consequences that are suggested by our model from those suggested by the ACC models. In our setting, if a high inflation equilibrium occurs when agents attach low probability to such an event, then there will be a decline in output because aggregate demand will fall and the average markup will increase. By contrast, in the ACC models, a switch from low inflation to high inflation will have little effect on the average markup or output, with the main difference being the extent of money demand distortions. Since the ACC models are essentially static ones, there is also another difference: there is no feedback between the likelihood that economic agents attach to future equilibria and the levels of inflation and output at a point in time. Accordingly beliefs about the future are of no bearing for current events. In our model, beliefs about future outcomes affect the nature of the current policy problem because firms setting their price in the current period care about both current and future monetary policy.

\section{Model}

The model economy that we study is a particular fully articulated "New Keynesian" framework, featuring monopolistic competition and nominal prices which are fixed for two periods. There is staggered pricing, with one-half of a continuum of firms adjusting price in each period. Since all of the firms have the same technology and face the same demand conditions, it is natural to think of all adjusting firms as choosing the same price. We impose this symmetry condition in our analysis.

There are many different types of New Keynesian models, which differ in terms of their implications for the extent of complementarity in price-setting. Our particular model assumes that (i) there is a constant elasticity demand structure originating from a Dixit-Stiglitz aggregator of differentiated products; (ii) there is a centralized labor market so that the common marginal cost for all firms is powerfully affected by aggregate demand; and (iii) preferences for goods and leisure display exactly offsetting income and substitution effects of wage changes, as is common in the literature on real business cycles. Kimball [1995] and Woodford [2002] have stressed that these 
assumptions make it difficult to generate complementarity between price-setters when there is an exogenous money stock. As we will, see our model has exactly zero complementarity in this situation. From our perspective, this is a virtue because it highlights the importance of the policy-based complementarity that arises from monetary policy under discretion. ${ }^{2}$

\section{$2.1 \quad$ Households}

There is a representative household, which values consumption $\left(c_{t}\right)$ and leisure $\left(l_{t}\right)$ according to a standard time separable expected utility objective,

$$
E_{t}\left\{\sum_{j=0}^{\infty} \beta^{j} u\left(c_{t+j}, l_{t+j}\right)\right\}
$$

with $\beta$ being the discount factor which is taken to be close to one. We assume that the momentary utility function takes the form

$$
u\left(c_{t}, l_{t}\right)=\log \left(c_{t}\right)+\chi l_{t}
$$

which implies that there are exactly off-setting income and substitution effects of wage changes. It also has some other convenient implications that we describe later.

As is standard in the analyses of imperfect competition macro models that follow Blanchard and Kiyotaki [1987] and Rotemberg [1987], we assume that consumption is an aggregate of a continuum of individual goods, $c_{t}=\left[\int_{0}^{1} c_{t}(z)^{(\varepsilon-1) / \varepsilon} d z\right]^{\varepsilon /(\varepsilon-1)}$. Households distribute their expenditure efficiently across these goods, resulting in constant-elasticity demands for individual products from each of the two types of firms which they will encounter in the equilibrium below:

$$
c_{j, t}=\left(\frac{P_{j, t}}{P_{t}}\right)^{-\varepsilon} c_{t}, j=0,1 .
$$

The subscript $j$ in (3) denotes the age of the nominal price, so that $P_{0, t}$ is the price set by firms in period $\mathrm{t}$ and $P_{1, t}$ is the price set by firms one period previously ( $\left.P_{1, t}=P_{0, t-1}\right)$. Likewise, $c_{j, t}$ is the period- $t$ demand for goods produced by a firm that set its price in period $t-j$. The price level which enters in these demands takes the form

$$
P_{t}=\left[\frac{1}{2} P_{0, t}^{1-\varepsilon}+\frac{1}{2} P_{1, t}^{1-\varepsilon}\right]^{\frac{1}{1-\varepsilon}}
$$

We assume that households also hold money to finance expenditure according to

$$
M_{t}=\int_{0}^{1} P_{t}(z) c_{t}(z) d z
$$

\footnotetext{
${ }^{2}$ Glomm and Ravikumar [1995] show how endogenous government policy of a different sort public education - can generate multiple equilbria.
} 
so that our model imposes a constant, unit velocity, in common with many macroeconomic analyses. ${ }^{3}$ We adopt this specification because it allows us to abstract from all the wealth and substitution effects that normally arise in optimizing models of money demand, so as to focus on the consequences of price-stickiness. With constant-elasticity demands for each good, the money-demand specification in (5) implies

$$
M_{t}=P_{t} c_{t}
$$

Since this is a representative agent model and since no real accumulation is possible given the technologies described below, we are not too explicit about the consumptionsaving aspect of the household's problem; it will be largely irrelevant in general equilibrium except for asset-pricing. We simply assume that there is a Lagrange multiplier that takes the form

$$
\lambda_{t}=\frac{\partial u\left(c_{t}, l_{t}\right)}{\partial c_{t}}=\frac{1}{c_{t}}
$$

and that households equate the marginal rate of substitution between leisure and consumption to the real wage rate prevailing in the competitive labor market, i.e.,

$$
w_{t}=\frac{\partial u\left(c_{t}, l_{t}\right) / \partial l_{t}}{\partial u\left(c_{t}, l_{t}\right) / \partial c_{t}}=\chi c_{t} .
$$

In each case, the second equality indicates the implications of the specific utility function introduced above.

\section{$2.2 \quad$ Firms}

Firms produce output according to a linear technology, where for convenience we set the marginal product of labor to one. So, for each type of firm, the production function is

$$
c_{j, t}=n_{j, t} .
$$

This implies that real marginal cost is unrelated to the scale of the firm or its type and is simply

$$
\psi_{t}=w_{t}
$$

and that nominal marginal cost is $\Psi_{t}=P_{t} \psi_{t}=P_{t} w_{t}$

Much of our analysis will focus on the implications of efficient price-setting by the monopolistically competitive firm. The adjusting firms in period t are assumed to set prices so as to maximize the expected present discounted value of their revenues, using the household's marginal utility as a (possibly stochastic) discount factor. That is, they choose $P_{0, t}$ to maximize their market value,

\footnotetext{
${ }^{3}$ We think of this quantity equation as the limiting version of a standard money demand function which occurs as the own return on money is raised toward the nominal interest rate (see King and Wolman [1999] for some additional discussion).
} 


$$
\left[\lambda_{t}\left(P_{0, t}-\Psi_{t}\right) c_{0, t}+\beta E_{t} \lambda_{t+1} \frac{P_{t}}{P_{t+1}}\left(P_{0, t}-\Psi_{t+1}\right) c_{1, t+1}\right] .
$$

As monopolistic competitors, firms understand that $c_{0, t}=\left(\frac{P_{0, t}}{P_{t}}\right)^{-\varepsilon} c_{t}$ and that $c_{1, t+1}=$ $\left(\frac{P_{0, t}}{P_{t+1}}\right)^{-\varepsilon} c_{t+1}$, but take $c_{t}, P_{t}, c_{t+1}$ and $P_{t+1}$ as not affected by their pricing decisions. The efficient price must accordingly satisfy

$$
P_{0, t}=\frac{\varepsilon}{\varepsilon-1} \frac{P_{t}^{\varepsilon-1} \Psi_{t}+\beta E_{t}\left(P_{t+1}^{\varepsilon-1} \Psi_{t+1}\right)}{P_{t}^{\varepsilon-1}+\beta E_{t}\left(P_{t+1}^{\varepsilon-1}\right)},
$$

where we again give the result under the specific momentary utility function. In fact, this reveals one motivation for the form of the particular utility function chosen. In general, both aggregate demand $\left(c_{t}\right)$ and the discount factor $\left(\lambda_{t}\right)$ affect the weights, but our choice of a utility function that is logarithmic in consumption means that these two effects exactly cancel out. With perfect foresight, the pricing equation can be written compactly as

$$
P_{0, t}=\frac{\varepsilon}{\varepsilon-1}\left[\left(1-\theta_{t, t+1}\right) \Psi_{t}+\theta_{t, t+1} \Psi_{t+1}\right] ;
$$

the optimal price is a constant markup $(\varepsilon /(\varepsilon-1))$ over a weighted average of nominal marginal cost over the two periods, where the weight on the future is

$$
\theta_{t, t+1}=\frac{\beta \lambda_{t+1} c_{t+1} P_{t+1}^{\varepsilon-1}}{\lambda_{t} c_{t} P_{t}^{\varepsilon-1}+\beta \lambda_{t+1} c_{t+1} P_{t+1}^{\varepsilon-1}}=\frac{\beta P_{t+1}^{\varepsilon-1}}{P_{t}^{\varepsilon-1}+\beta P_{t+1}^{\varepsilon-1}} .
$$

The weights on current and future nominal marginal cost represent the shares of marginal revenue associated with the current and future periods.

\subsection{Defining Complementarity in Price Setting}

The standard definition of complementarity - contained, for example, in Cooper and John [1988]- is that the optimal action of one decision-maker is increasing in the actions of other similar decision-makers. In our context, we are interested in complementarity in price-setting in equation (11). The left-hand side of this expression is the action of the particular decision-maker under study: the optimal price of an individual monopolistically competitive firm that is currently making a price adjustment. Other monopolistically competitive firms are also simultaneously adjusting prices: these firms take an action $P_{0, t}$ that influences the right-hand of (11). The price chosen by the representative adjusting firm influences the price level directly because $P_{t}=\left[\frac{1}{2} P_{0, t}^{1-\varepsilon}+\frac{1}{2} P_{1, t}^{1-\varepsilon}\right]^{\frac{1}{1-\varepsilon}}$ and may also affect current nominal marginal cost. Given that prices are sticky, there can be real effects of variations in the price level, so that these could influence nominal marginal cost. Finally, the weights on the present and the future in (11) also depend on the price level. To determine whether there is 
complementarity, we must work through these mechanisms and determine the sign of the relevant partial derivative. The extent of complementarity will depend on the behavior of the monetary authority.

\subsection{Timing}

The sequence of actions within a period is as follows. In the first stage, the monetary authority chooses the money stock, $M_{t}$, taking as given $P_{1, t}$, the price set by firms in the previous period. In the second stage, adjusting firms set prices $\left(P_{0, t}\right)$. Simultaneously, wages are determined and exchange occurs in labor and goods markets.

There are two important consequences of these timing assumptions. First, since price-setters move after the monetary authority, they cannot be surprised by the monetary authority during the initial period that their price is in effect. Accordingly, the monetary authority faces an economy in which it can surprise some agents (those with pre-set prices) but not others (those adjusting prices) within a period. This gives rise to a relative price distortion across firms in the discretionary equilibrium that we construct, which in turn means that there is an interior solution for the monetary authority's choice problem. If we reversed the timing order so that the monetary authority moved last, we conjecture that there would not be a discretionary equilibrium unless some other aspect of the economy were modified, such as allowing firms to reset their prices after paying an adjustment cost. ${ }^{4}$ Second, the fact that the price-setters move after the monetary authority means that there is the potential for more than one equilibrium price to correspond to a given monetary policy action.

\subsection{Complementarity with an exogenous money stock}

We now consider a situation in which $M_{t}=M_{t+1}=M$. Under the assumptions of our model, it turns out to be easy to investigate the influence of other adjusting firm's actions, i.e., to compute the effect of $P_{0, t}$ on the right-hand side of (11). With the constant velocity assumption $\left(P_{t} c_{t}=M_{t}\right)$ and with the particular utility function, $\Psi_{t}=P_{t} w_{t}=P_{t}\left(\chi c_{t}\right)$. Hence, equilibrium nominal marginal cost is exactly proportional to the money stock, $\Psi_{t}=\chi M_{t}$. Since the nominal money stock is assumed constant over time, nominal marginal cost is also constant over time and (11) becomes

$$
P_{0, t}=\frac{\varepsilon}{\varepsilon-1} \chi M .
$$

This equilibrium relationship means that there is an exactly zero effect of $P_{0, t}$ on the right-hand side: there is no complementarity in price-setting in this model when the nominal money supply is constant.

\footnotetext{
${ }^{4}$ The nonexistence of a discretionary equilibrium is a feature of Ireland's [1997] analysis of a model in which all prices are set simultaneously, before the monetary authority determines the current money supply.
} 


\subsection{Summarizing the economy by $p_{0}$ and $m$}

Under discretionary policy, the monetary authority will not choose to keep the nominal money supply constant. Therefore, the optimal pricing condition (11) will not simplify to a static equation. In general, however, equilibrium will be a function of just two variables: a measure of the price set by adjusting firms and a measure of monetary policy. We construct these variables by normalizing nominal prices and money by the single nominal state variable in this economy, the price set by firms in the previous period $\left(P_{1, t}=P_{0, t-1}\right)$. Define the normalized money supply as

$$
m_{t}=M_{t} / P_{1, t},
$$

and the normalized price set by adjusting firms in the current period as

$$
p_{0, t}=P_{0, t} / P_{1, t}
$$

We can then express all variables of interest as functions of these two normalized variables. From (4), the normalized price level is a function of only $p_{0, t}$ :

$$
\frac{P_{t}}{P_{1, t}}=g\left(p_{0, t}\right)
$$

where

$$
g\left(p_{0, t}\right) \equiv\left[\frac{1}{2} p_{0, t}^{1-\varepsilon}+\frac{1}{2}\right]^{\frac{1}{1-\varepsilon}} .
$$

Aggregate demand is a function of both $p_{0, t}$ and $m_{t}$ :

$$
c_{t}=c\left(p_{0, t}, m_{t}\right) \equiv \frac{m_{t}}{g\left(p_{0, t}\right)} .
$$

This follows from the money demand equation:

$$
c_{t}=\frac{M_{t}}{P_{t}}=\frac{M_{t}}{P_{1, t}} \frac{P_{1, t}}{P_{t}}=\frac{m_{t}}{g\left(p_{0, t}\right)} .
$$

Further, since $n_{t}=\left[\frac{1}{2} n_{0, t}+\frac{1}{2} n_{1, t}\right]=\left[\frac{1}{2} c_{0, t}+\frac{1}{2} c_{1, t}\right]$, we can use the individual demands together to show that total labor input is also pinned down by $p_{0, t}$ and $m_{t}$ :

$$
n_{t}=n\left(p_{0, t}, m_{t}\right) \equiv \frac{1}{2} \cdot c\left(p_{0, t}, m_{t}\right) \cdot\left[g\left(p_{0, t}\right)\right]^{\varepsilon} \cdot\left(p_{0, t}^{-\varepsilon}+1\right) .
$$

Leisure is the difference between the time endowment and labor input. Marginal cost is

$$
\psi_{t}=w_{t}=\frac{\partial u\left(c_{t}, l_{t}\right) / \partial l_{t}}{\partial u\left(c_{t}, l_{t}\right) / \partial c_{t}}=\chi c_{t}=\psi\left(m_{t}, p_{0, t}\right)
$$


Another variable of interest is the gross inflation rate, $P_{t+1} / P_{t}$. It is determined by current and future $p_{0}$ :

$$
\frac{P_{t+1}}{P_{t}}=\pi\left(p_{0, t}, p_{0, t+1}\right) \equiv \frac{g\left(p_{0, t+1}\right)}{g\left(p_{0, t}\right)} p_{0, t} .
$$

This follows directly from writing the inflation rate as a ratio of normalized variables:

$$
\frac{P_{t+1}}{P_{t}}=\frac{P_{t+1} / P_{0, t}}{P_{t} / P_{1, t}} \frac{P_{0, t}}{P_{1, t}}=\frac{g\left(p_{0, t+1}\right)}{g\left(p_{0, t}\right)} p_{0, t} .
$$

In a steady state, there is thus a simple relationship between inflation and the relative price, $\pi=p_{0}$.

\subsection{Two distortions and monetary policy}

The monetary authority in this model faces two distortions that are present in the private economy and can be influenced by its actions. First, there is a markup distortion that represents the wedge between price and marginal cost: it has consequences similar to those of a tax on labor income. The extent of this average markup is just the reciprocal of real marginal cost,

$$
\mu_{t}=\frac{1}{\psi_{t}}=\frac{1}{w_{t}}=\frac{\partial u\left(c_{t}, l_{t}\right) / \partial c_{t}}{\partial u\left(c_{t}, l_{t}\right) / \partial l_{t}}=\frac{1}{\chi c_{t}} .
$$

From the derivations above, the markup depends on $p_{0, t}$ and $m_{t}: \mu_{t}=g\left(p_{0, t}\right) /\left(\chi m_{t}\right)$. Second, there is a relative price distortion that represents a wedge between inputs and outputs:

$$
n_{t} / c_{t}=\delta\left(p_{0, t}\right) \equiv \frac{1}{2} \cdot\left[g\left(p_{0, t}\right)\right]^{\varepsilon} \cdot\left(p_{0, t}^{-\varepsilon}+1\right) .
$$

The relative price distortion depends solely on $p_{0, t}$. It takes on a value of unity at $p_{0, t}=1$ (this would be the case in a zero inflation steady state) and is higher for other values of $p_{0, t}$. The trade-off that the monetary authority typically faces between these two distortions is that choosing a higher money supply decreases the markup (good) and raises the relative price distortion (bad).

Just as we showed above that all real variables could be described in terms of $p_{0}$ and $m$, the distortions can be described similarly. The summary role of $p_{0}$ and $m$, together with the fact that at any point in time the monetary authority can choose $m$ (i.e. choosing $m$ in the current period is no different than choosing $M$ ) has a strong implication for the analysis of discretionary monetary policy. ${ }^{5}$ It implies that the level of the predetermined nominal price $P_{1, t}$ does not restrict the outcomes a

\footnotetext{
${ }^{5}$ It is important not to misinterpret the parenthetical statement: any choice of $M_{t}$ can be replicated by choosing $m_{t}=M_{t} / P_{1, t}$. However, a policy of keeping $M_{t}$ constant is not the same as a policy of keeping $m_{t}$ constant.
} 
discretionary policymaker can achieve, as long as the monetary authority in future periods behaves in the same manner. ${ }^{6}$

We now analyze outcomes under monetary discretion, proceeding in three steps (with each a separate section of the paper). We begin by studying perfect foresight settings. In section 3, we detail the nature of perfect foresight private sector equilibria under a particular class of monetary policy rules. In section 4, we describe a full discretionary equilibrium - with optimization by the monetary authority - in which policy is shown to be in this class of rules. Finally, in section 5, we discuss stochastic equilibria, with an optimizing private sector and monetary authority.

\section{Equilibrium with homogeneous policy}

We begin by studying the nature of equilibrium price-setting $\left(p_{0, t}\right)$ given an arbitrary action by the monetary authority and given perfect foresight. We assume that the monetary authority adopts a policy rule of the form

$$
M_{t}=m_{t} P_{0, t-1}
$$

where $m_{t}$ is viewed as the policy variable. That is, the money supply is proportional to the prices that adjusting firms set one period ago with a constant of proportionality $m_{t}$. We call this a homogenous monetary policy rule. This form of monetary accommodation of past nominal variables is characteristic of optimal monetary policy under discretion, for the following reason. The monetary authority is concerned about the real variables that enter in private agents' utility. It takes past prices as given, and there is no mechanism by which the level of nominal predetermined prices necessarily constrains the behavior of a discretionary policymaker. ${ }^{7}$ Thus, if we viewed $M$ instead of $m$ as the policy instrument, we would find that the optimizing monetary authority adjusted $M_{t}$ proportionally to $P_{1, t}$, just as is specified in (16). It will economize slightly on notation and computation to view $m_{t}$ as the policy instrument, and there is no loss in generality. In a discretionary equilibrium, $m_{t}$ will be chosen to maximize welfare; in this section $m_{t}$ is arbitrary. ${ }^{8}$

A homogenous money supply rule means that future monetary policy depends on the price set by adjusting firms today,

$$
M_{t+1}=m_{t+1} P_{0, t} .
$$

\footnotetext{
${ }^{6}$ If the future monetary authority paid attention to nominal levels, it might be optimal for the current monetary authority to do the same. We do not consider equilibria with this property.

${ }^{7}$ The word "necessarily" appears because one could construct non-Markov equilibria in which all agents agreed that $P_{1, t}$ did constrain the monetary authority. See previous footnote. We do not study such equilibria.

${ }^{8}$ By contrast, under commitment, the monetary authority commits not to respond to $P_{1, t}$, and the choice is over sequences of $M_{t}$. King and Wolman (1999) study optimal policy with commitment in the model used here.
} 
Consequently, under homogeneous policy and using the preferences introduced above, it follows from the efficient price-setting condition (11) that the nominal price set by adjusting firms $\left(P_{0, t}\right)$ satisfies

$$
P_{0, t}=\frac{\varepsilon \chi}{\varepsilon-1}\left(\left(1-\theta_{t, t+1}\right) m_{t} P_{1, t}+\theta_{t, t+1} m_{t+1} P_{0, t}\right)
$$

in equilibrium. The derivation of (17) from (11) involves (i) using the fact that nominal marginal cost is $\Psi_{t}=P_{t} \chi c_{t}$ given the specific utility assumption; (ii) imposing monetary equilibrium $\left(M_{t}=P_{t} c_{t}\right)$; and (iii) imposing the homogenous form of the monetary policy rule $\left(M_{t}=m_{t} P_{1, t}\right)$. From (17), the normalized price set by adjusting firms $\left(p_{0, t}\right)$ satisfies

$$
\begin{aligned}
p_{0, t} & =\left(\frac{\varepsilon \chi}{\varepsilon-1}\right)\left(\left(1-\theta_{t, t+1}\right) m_{t}+\theta_{t, t+1} m_{t+1} p_{0, t}\right) \\
& \equiv r\left(p_{0, t}, m_{t}, p_{0, t+1}, m_{t+1}\right) .
\end{aligned}
$$

The weight on future nominal marginal cost, which was defined in (12), can be written in terms of current and future normalized prices as

$$
\theta\left(p_{0, t}, p_{0, t+1}\right)=\frac{\beta \pi\left(p_{0, t}, p_{0, t+1}\right)^{\varepsilon-1}}{1+\beta \pi\left(p_{0, t}, p_{0, t+1}\right)^{\varepsilon-1}} .
$$

where we are now explicit about how $\theta_{t, t+1}$ depends on the present and the future. Equation (18) is a nonlinear difference equation in $p_{0}$ and $m$ that must be satisfied in a perfect foresight equilibrium with homogeneous policy.

We view $p_{0, t}$ on the left-hand side of (18) as describing what an individual firm finds optimal given the actions of other price-setters and the monetary authority. On the right hand side, $p_{0, t}$ then represents all other adjusting firms' pricing behavior, and the function on the right hand side represents the implications of those firms' behavior for the marginal revenues and costs of an individual firm. In other words, $r($.$) is a best-response function for the individual firm. We restrict attention to sym-$ metric equilibria, so that prices chosen by all adjusting firms are identical. We define complementarity in terms of a positive partial derivative of the response function with respect to its first argument. That is: with perfect foresight, there is complementarity if $\partial r\left(p_{0, t}, m_{t}, p_{0, t+1}, m_{t+1}\right) / \partial p_{0, t}>0$.

In sections 3.2 and 3.3 below, we will make intensive use of the perfect-foresight best-response function (18). First, we will use it to describe point-in-time equilibria; this involves characterizing the fixed points for $p_{0, t}$, taking as given $m_{t}, m_{t+1}$, and $p_{0, t+1}$. Second, we will use it to determine the model's steady-state equilibria under constant arbitrary policy. That is, we will impose $p_{0, t}=p_{0, t+1}$ and $m_{t}=m_{t+1}=m$ and determine the equilibrium value(s) (fixed points) for $p_{0}$. Both of these exercises will then serve as inputs to our analysis of discretionary equilibria. There, (18) will summarize private sector equilibrium for any action that the monetary authority 
contemplates, under perfect foresight. ${ }^{9}$ With uncertainty, (18) will not hold exactly, but the mechanisms discussed here will still be relevant.

\subsection{Complementarity under homogeneous monetary policy}

There are two mechanisms for complementarity in (17) and (18) that will be operative in our analysis of both point-in-time and steady-state equilibria. First, holding fixed the weights, $P_{0, t}$ has a positive effect on the right-hand side in (17): it enters linearly

with a coefficient of $\left(\frac{\varepsilon \chi}{\varepsilon-1}\right) \theta_{t, t+1} m_{t+1}$, which is positive because firms are forwardlooking and the monetary authority raises nominal $M_{t+1}$ proportionately with $P_{0, t}$. Hence the specification of monetary policy has introduced some complementarity into an economy in which it was previously absent.

Second, the weights in these expressions vary with the current price $P_{0, t}$ (or its normalized counter part $\left.p_{0, t}\right)$. This additional channel plays an important role in our analysis. A reference value for the weight $\theta_{t, t+1}$ is one-half, since (12) implies that the weight is $\beta /(1+\beta)$ with $\beta$ close to one if if $P_{t}=P_{t+1}$. An upper bound on this weight is one: this is a situation where firms place full weight on the future. Increases in the weight raise the extent of the effect discussed above, i.e., they raise the coefficient $\left(\frac{\varepsilon \chi}{\varepsilon-1}\right) \theta_{t, t+1} m_{t+1}$ that measures the extent of complementarity. The second mechanism is then that an increase in $P_{0, t}$ (or its normalized counterpart $p_{0, t}$ ) raises the weight on the future. This occurs because a firm's profits are not symmetric around its optimal price. As the firm's relative price rises, its profits decline gradually, asymptotically reaching zero as the price goes to infinity. By contrast, as the price falls, the firms profits decline sharply toward zero and may even become highly negative if the firm is not allowed to shut down its operations. ${ }^{10}$ Thus, when $P_{0, t}$ increases for all other firms, future monetary accommodation - and the associated higher nominal price set by firms in the future - automatically lower's the firm's future relative price. The costliness of a low relative price leads the firm to put increased weight on future marginal cost.

\subsection{Equilibrium analysis of steady states}

To characterize steady-state equilibria for arbitrary constant, homogeneous monetary policies, we impose constant $m$ and $p_{0}$ on the right hand side of (18). Steady-state equilibria are fixed points of the resulting steady-state best-response function for $p_{0}$ :

$$
p_{0}=\frac{\varepsilon \chi}{\varepsilon-1} m\left[1-\theta\left(p_{0}, p_{0}\right)+\theta\left(p_{0}, p_{0}\right) p_{0}\right]
$$

\footnotetext{
${ }^{9}$ If we impose $m_{t}=m_{t+1}$ but allow $p_{0 t}$ to differ from $p_{0, t+1}$, then (18) describes the dynamics of $p_{0, t}$ for constant homogeneous policy. Such analysis might reveal interesting dynamics. However, it is not an input into our analysis of discretionary equilibrium.

${ }^{10}$ At this point in the analysis, we do not explicitly take into account the shut-down possibility. But, when we calculate discretionary equilibria, we do verify that the equilibria are robust to allowing firms to shut down.
} 
with a weight on the future of

$$
\theta\left(p_{0}, p_{0}\right)=\frac{\beta p_{0}^{\varepsilon-1}}{1+\beta p_{0}^{\varepsilon-1}} .
$$

Fixed points of the steady-state best-response function are constructed by simultaneously varying current and future $p_{0}$ on the right hand side. This is in contrast to fixed points of the basic point-in-time best-response function, which are constructed holding fixed $p_{0, t+1}$.

\subsubsection{Uniqueness occurs at zero inflation}

A zero inflation steady state involves $p_{0}=1$. Such a steady state exists when the normalized quantity of money is $m^{*} \equiv\left(\frac{\varepsilon}{\varepsilon-1} \chi\right)^{-1}$. In this case, the weight on the future is $\theta=\beta /(1+\beta)$, which is roughly one-half. The zero-inflation steady state is asymptotically optimal under full commitment in this model (see King and Wolman [1999]) and provides an important benchmark. Furthermore, if $m=m^{*}$, zero inflation is the unique steady state; that is, $p_{0}=1$ is the unique solution to (20) when $m=m^{*}$.

\subsubsection{Multiplicity or nonexistence must occur with positive inflation}

We refer to any $m>m^{*}$ as an inflationary monetary policy, because if inflation is positive in a steady state, then $m>m^{*}$, as we now show. From (20), given that $\pi=p_{0}$ in steady state, we have

$$
m=\frac{1}{\left(\frac{\varepsilon}{\varepsilon-1} \chi\right)} \frac{\pi}{[1-\theta+\theta \pi]}=\frac{1}{\left[\theta+(1-\theta)\left(\frac{1}{\pi}\right)\right]} m^{*} .
$$

Thus, $\pi>1$ if and only if $m>m^{*}$.

Proposition 1 states that under an arbitrary inflationary monetary policy, for low values of $m$ there are two steady-state equilibrium values of $p_{0}$. For high values of $m$, no steady-state equilibrium exists. In a knife edge case there is a unique steady-state equilibrium.

Proposition 1 There exists an $\widetilde{m}>m^{*}$ such that for $m \in\left(m^{*}, \widetilde{m}\right)$ there are two steady-state equilibria, and for $m>\widetilde{m}$ there is no steady-state equilibrium.

Proof. see Appendix.

From (20), steady-state equilibria for a given $m$ are fixed points of $r\left(p_{0} ; m\right)$, where we write the best-response function as

$$
r\left(p_{0}, m\right)=\frac{m}{m^{*}} \cdot\left[\left(1-\theta\left(p_{0}\right)\right)+\theta\left(p_{0}\right) \cdot p_{0}\right]
$$

for the discussion of proposition 1. 
Figure 1 provides the basis for a heuristic discussion of Proposition 1, based on the best-response function $r()$. The dashed line in Figure 1 is the $45^{\circ}$ line; when $r$ () crosses this line the action of a representative adjusting firm (the horizontal axis) coincides with the optimal action of an individual firm as described by $r()$. The solid line is $r()$ for $m>m^{*}$. When $m=m^{*}$ it is easy to see from (22) that there is one steady state, and it occurs at $p_{0}=1$. An increase in $m$ shifts $r()$ upwards. It is thus clear that $p_{0}=1$ is not an equilibrium point with $m>m^{*}$, but that there is a prospect for an intersection point somewhere to the right as in the case illustrated in Figure 1. At any such "low" stationary equilibrium, it must be the case that the slope is less than one (if $r\left(p_{0},.\right)$ crosses the $45^{\circ}$ line) or the slope is exactly equal to one (if it is a tangency). Let us call this first equilibrium $p_{0}$.

Suppose the slope at a "low" stationary equilibrium is less than one, so that it is not a tangency and corresponds to the case illustrated in Figure 1. As $p_{0}$ becomes arbitrarily large, $\theta \rightarrow 1$. For large $p_{0}$, then, it follows that $r\left(p_{0},.\right)$ approaches the line $\left(m / m^{*}\right) p_{0}$ from below. For high enough $p_{0}$ then, $r\left(p_{0},.\right)>p_{0}$ since we are considering an inflationary monetary policy $\left(m>m^{*}\right)$. We have assumed there was a fixed point at which $\partial r / \partial p_{0}<1$, and we have shown that $r()$ lies above the $45^{0}$ line for high enough $p_{0}$, so there must be some other "high" $p_{0}$ for which there is an equilibrium $r\left(\overline{p_{0}}\right)=\overline{p_{0}}$. If $m$ is high enough, the first fixed point does not exist, and $r()$ lies everywhere above the $45^{\circ}$ line. We label the two equilibria with an asterisk $\left(^{*}\right)$ and carry them over to our discussion below.

There are two mechanisms at work to produce multiple steady-state rates of inflation for arbitrary constant, homogeneous monetary policy. The first is that monetary policy is accommodative: if higher prices are set by other firms today, the future nominal money stock will be higher in proportion. The second is that if all other firms raise prices today and in the future, then the future inflation rate will rise and a single firm today places higher weight on future nominal marginal costs, so that future monetary endogeneity becomes more influential on current price-setting. Looking ahead, the discretionary equilibria we will construct below will involve constant, homogeneous monetary policy. Necessarily, then, there will be multiple steady-state equilibria under discretion. However, in order to construct those equilibria we cannot rely on the steady-state best-response function.

\subsection{Point-in-time equilibria}

Solving the monetary authority's problem under discretion means computing the point-in-time equilibria that correspond to all possible current policy actions, and then picking the best action. Before studying this topic in detail in section 4 , we here begin by characterizing point-in-time equilibria for an arbitrary policy action in the current period. Point-in-time equilibrium refers to the values of $p_{0, t}$ that solve (18) for given current and future monetary actions, and a given future price $p_{0, t+1}$. The mechanisms described earlier lead to the potential for multiple point-in-time equilibria. We 
assume that the future money supply is given by $m_{t+1} \in\left(m^{*}, \widetilde{m}\right)$, (i.e. steady-state equilibria do exist for the assumed value of $m_{t+1}$ and are inflationary) and that the future relative price is consistent with one of the two steady-state equilibria that may prevail if that level of $m_{t+1}$ is maintained forever. Under these assumptions, there are either two equilibria in the current period or equilibrium does not exist. Again, in a knife edge case equilibrium is unique.

Proposition 2 If $m_{t+1} \in\left(m^{*}, \widetilde{m}\right)$ is fixed, then there exists $\breve{m}$ such that for $m_{t}<\breve{m}$ there are two equilibria in period $t$, and for $m_{t}>\breve{m}$ equilibrium does not exist in period $t$.

Proof. see appendix for a sketch.

Point-in-time equilibria are fixed points of the best-response function for current period price-setters, which we write without time subscripts, using superscript prime to denote next period:

$$
p_{0}=r\left(p_{0}, m, p_{0}^{\prime}, m^{\prime}\right)=\frac{1}{m^{*}}\left[\left(1-\theta\left(p_{0}, p_{0}^{\prime}\right)\right) m+\theta\left(p_{0}, p_{0}^{\prime}\right) m^{\prime} p_{0}\right]
$$

No expectation operator appears because we are assuming, for the purposes of this section, that there is no uncertainty about future $m$ and - more importantly - future $p_{0}$. Multiplicity of point-in-time equilibria occurs for much the same reason as multiplicity of steady states. Because the future nominal money supply is endogenous, the current price of other firms has an effect of more than one-for-one on a single firm's desired price if agents weight the future heavily, as they do if $m^{\prime}>m^{*}$ and $p_{0}$ is high enough. Note that as long as the future money supply is inflationary, there will be multiple equilibria even for noninflationary current values of the money supply.

Figure 2 illustrates the multiplicity of point-in-time equilibria for $m=m^{\prime}>m^{*}$, for two different beliefs about future $p_{0}$. As above, the dashed line is the $45^{0}$ line that identifies fixed points: the two points marked with asterisks ( (**) on the $45^{\circ}$ line are the steady states from Figure 1. The solid line is the best-response function when agents expect $p_{0}$ in the future, with certainty. The low steady state is a point-in-time equilibrium when agents expect $\underline{p}_{0}$ in the future, but the high steady state is not, because in that steady state agents expect $\bar{p}_{0}$ rather than $p_{0}$ in the future. In fact, the second point-in-time equilibrium must be at a higher $\bar{p}_{0}$, because expectations make the future less important than in the steady-state analysis of Figure 1: a larger increase in the weight on the future is required for the second fixed point to occur. The dotted line shows the best-response function when agents expect $\bar{p}_{0}$ in the future, with certainty. In this case the higher of the two steady-state equilibria survives as a point-in-time equilibrium, but the the low-inflation point-in-time equilibrium is now higher than the low-inflation steady state.

From (23), note that for given $m^{\prime}$, lower $m$ drives down the lower price equilibrium and drives up the higher price equilibrium. Lower current $m$ shifts the best-response function down, with lower current marginal cost reducing the firm's optimal price 
for any price set by other firms. The lower fixed point falls, but because the basic properties of the response function are unchanged, there is still a second fixed point, now at a higher level of $p_{0}$; at this high level of $p_{0}$, high future marginal cost offsets the lower current marginal cost. Current monetary policy actions thus affect the two equilibria in very different ways.

Figure 2 illustrates that beliefs about both current and future equilibrium selection can affect the opportunities available to a discretionary monetary authority. Raising the current money supply shifts out the best-response function for firms, resulting in a lower high- $p_{0}$ equilibrium and higher low- $p_{0}$ equilibrium. The likelihood of each equilibrium in the present will thus alter the trade-off facing the monetary authority. Beliefs about future equilibrium selection shift the current period best-response function for a given current money supply, and thus also alter the trade-off facing the current monetary authority.

\section{Discretion under perfect foresight}

In a perfect foresight discretionary equilibrium, the current monetary authority sets the money stock to maximize the representative private agent's welfare, subject to

1. The behavior of the future monetary authority $\left(m^{\prime}\right)$.

2. The behavior of firms in the future $\left(p_{0}^{\prime}\right)$.

3. Optimal pricing by firms in the current period $\left(p_{0}\right)$. The monetary authority must have beliefs about the selection rule used to determine $p_{0}$ when a contemplated value of $m$ leads to multiple equilibrium values of $p_{0}$.

Two conditions define a stationary perfect foresight equilibrium with discretion: (i) the current and future monetary authority each choose the same action; and (ii) the selection rule specifies that only one equilibrium will prevail in every period. It is common knowledge which equilibrium will prevail.

As we noted above, it is the essence of discretion in monetary policy that certain predetermined nominal variables are taken as given by the monetary authority. Here, the current money supply is set proportionally to the previously set price, $P_{1, t}=$ $P_{0, t-1}$. This leads us to view $m$ as the monetary authority's choice variable. Our analysis of equilibrium under arbitrary choice of $m$ revealed that in general there were either two point-in-time equilibria or no point-in-time equilibria, as long as future policy was expected to be inflationary. This leads us to expect multiple discretionary equilibria. In this section we analyze discretionary equilibria where there is a constant probability of 1.0 on one of the two private sector equilibria. ${ }^{11}$

\footnotetext{
${ }^{11}$ Wolman [2001] determines the (unique) optimal allocation that can be achieved by a monetary authority that is constrained by discretion, using a primal approach that is silent on how the
} 


\subsection{Constructing Discretionary Equilibria}

We look for a stationary, discretionary equilibrium, which is a value of $m$ that maximizes $u(c, l)$ subject to the constraints above when $m^{\prime}=m .{ }^{12}$ We have used two computational approaches to find this fixed point. A comparison of the two approaches is revealing about the nature of the multiple equilibria we encounter.

The first computational method involves iterating on steady states. We assume that all future monetary authorities follow some fixed rule $m^{\prime}$. Next, we determine the steady state that prevails including the value of $p_{0}^{\prime}$. Then, we confront the current monetary policy authority with these beliefs and ask her to optimize, given the constraints including the selection rule. If she chooses an $m$ such that $\left|m-m^{\prime}\right|$ is sufficiently small, then we have an approximate fixed point. If not, then we adjust the future monetary policy rule in the direction of her choice and go through the process again until we have achieved an approximate fixed point. This approach conceptually matches our discussion throughout the text, but leaves open an important economic question: are the equilibria that we construct critically dependent on the infinite horizon nature of the problem?

The second computational method involves backward induction on finite horizon economies. We begin with a last period, in which firms are not forward-looking in their price setting and deduce that there is a single equilibrium, including an optimal action for the monetary authority $m_{T}>m^{*}$ and a unique equilibrium relative price $p_{0, T}$. Then, we step back one period, taking as given the future monetary action and the future relative price. We find that there are two private sector equilibria. In fact, this is inevitable, because the first step backwards creates a version of our point-intime analysis above. Consequently, this approach establishes that the phenomena are associated with forward-looking pricing and homogenous monetary policy, rather than with an infinite horizon. To construct stationary nonstochastic equilibria using this approach, we can iterate backwards from the last period, computing the optimal policy, $\left\{m_{T}, m_{T-1}, \ldots.\right\}$ and stop the process when $\left|m_{t+1}-m_{t}\right|$ is small, taking $m_{t}=m$ as an approximate fixed point.

The numerical examples that we study next have the following common elements. The demand elasticity $(\varepsilon)$ is 10 , implying a gross markup of 1.11 in a zero inflation steady state. The preference parameter $(\chi)$ is 0.9 , and for convenience we set the time endowment to 5 . Taken together with the markup, this implies that agents will work one fifth of their time $(n=1)$ in a zero inflation steady state. With zero inflation, $c=n=1$ since there are no relative price distortions, and thus $m^{*}=1$. Further, leisure $(l)$ is then $5-c$. Accordingly, in a zero inflation stationary state, utility is

monetary authority brings about this allocation using monetary instruments. This allocation is the one associated with the low- $p_{0}$ equilibrium described here. Our work thus shows that a monetary authority which seeks to implement the optimal real allocation using a money stock rule leaves itself vulnerable to multiple equilibria.

${ }^{12}$ Dotsey and Hornstein [2003] use linear-quadratic methods to study the monetary policy problem under discretion. We believe that these essentially rule out the phenomena encountered in this paper. 
just $\ln (1)+0.9 \cdot(5-1)$. A first-best outcome would dictate that $u(c, l)$ be maximized subject to $c=(1-l)$. For the specified preferences, this leads to a first order condition

$\frac{1}{n}=\chi$ or an efficient level of work $(n)$ of 1.11 . So, the increase in work from cutting the gross markup to one is $11.1 \%$.

\subsection{Optimistic Equilibrium}

If the discretionary monetary authority knows that the low equilibrium will prevail, then its problem is to maximize

$$
u(c, l)+v\left(\underline{p_{0}} ; m^{\prime}\right)
$$

where $v\left(\underline{p_{0}} ; m^{\prime}\right)$ denotes the future utility that corresponds to a steady state with $m^{\prime}$ and selection of the low- $p_{0}$ equilibrium with probability 1.0. The maximization is subject to

$$
\begin{aligned}
c & =c\left(m, \underline{p_{0}}\right) \\
l & =l\left(m, \underline{p_{0}}\right) \\
\underline{p_{0}} & =r\left(\underline{p_{0}}, \underline{p_{0}}{ }^{\prime}, m, m^{\prime}\right),
\end{aligned}
$$

where $r()$ denotes the response function on the right hand side of (23), and the presence of $\underline{p_{0}}$ instead of $p_{0}$ is meant to imply that we place probability one on the low- $p_{0}$ fixed point of the response function. The monetary authority understands that future utility and current price determination is influenced by the actions of the future monetary authority, but has no way of influencing its behavior or the future price that will prevail. So, the monetary authority maximizes current period utility.

\subsubsection{Exploiting initial conditions}

Figure 3 provides some insight into the nature of the monetary authority's choice when it knows that the $p_{0}$ equilibrium will prevail for all time. For this figure, we assume that future monetary policy is noninflationary $\left(m^{\prime}=m^{*}, p_{0}^{\prime}=1\right)$. The current monetary authority optimally adopts an inflationary monetary policy (choosing $m>m^{*}=1$ ) because it can reduce the markup and stimulate consumption toward the first-best level. It does not completely drive the gross markup to one because an increase in $m$ produces relative price distortions. While the relative price distortions are negligible near the noninflationary steady state, they increase convexly as monetary policy stimulates the economy. Figure 3 illustrates the sense in which New Keynesian models capture the incentive for stimulating the economy at zero inflation, as described in Kydland and Prescott [1977] and Barro and Gordon [1983].

\subsubsection{An inflation bias equilibrium}

Figure 4 displays the consistent steady-state equilibrium, in which agents correctly forecast the incentives of the monetary authority. Panel A shows the policymaker's 
objective function, which can be thought of as an indirect utility function: the relevant portion for the current discussion is the solid line, which reaches a maximum at the value of $m / m^{*}=1.01$. This implies a stationary relative price $\left(p_{0}\right)$ of 1.022 , which is determined along the lines of Figure 2 with agents expecting $p_{0}^{\prime}=p_{0}$ and $m^{\prime}=m$. Given that there is a steady state, $\pi=p_{0}$ and this relative price thus implies an inflation rate of $2.2 \%$ per quarter. At this inflation rate, the monetary authority faces sufficiently increasing marginal relative price distortions that it chooses not to further increase $m$ in an effort to further reduce the markup. Notably, the stationary markup departs little from its value at zero inflation. Stationary consumption is $99.96 \%$ of its zero inflation value, so that the markup has changed negligibly (recall that the markup and consumption are directly related by $\mu_{t}=\left(c_{t} \chi\right)^{-1}$ with the preference specification used here).

\subsection{Pessimistic Equilibrium}

We next suppose that the monetary authority instead knows that the high $p_{0}$ equilibrium will always prevail. Its incentives are sharply different. Looking at Figure 4, we can see these incentives in the dashed lines, which describe a non-equilibrium situation in which the private sector and the monetary authority assume that the future is described by $\underline{m}, \underline{p}_{0}$ while the present is described by $\bar{p}_{0}$. The monetary authority has a clear incentive to raise $m>\bar{m}$ since this lowers the markup and relative price distortions, with utility being maximized when $m$ is sufficiently high that there is exactly a tangency equilibrium in the temporary equilibrium analysis of Figure 2. Here the monetary authority "takes policy to the limit" of the set of equilibria that are imposed as its constraints. Because Figure 4 assumes optimism (that is, the low- $p_{0}$ outcome occurs with probability one), there are some inconsistencies in using Figure 4 to discuss an equilibrium with pessimistic expectations. Notably, the monetary authority can lower the markup to less than one, in which case some of the firms in the economy are making losses. But the picture tells the right story: nearer the consistent discretionary equilibrium that is described by a level $\bar{m}$, the monetary

authority still has the same incentives to raise $m$, but it does so without producing the curious behavior of the markup shown here.

In fact, it is not necessary to make a complicated set of fixed point computations in this case. A tangency equilibrium is one in which $\frac{\partial r\left(p_{0, t}, m_{t}, p_{0, t+1}, m_{t+1}\right)}{\partial p_{0, t}}=1$. Therefore, we can simply solve the stationary version of the equation,

$$
p_{0, t} \frac{\partial r\left(p_{0, t}, m_{t}, p_{0, t+1}, m_{t+1}\right)}{\partial p_{0, t}}=r\left(p_{0, t}, m_{t}, p_{0, t+1}, m_{t+1}\right)
$$

to calculate the equilibrium value of $p_{0}$ (this is one equation in one unknown $p_{0}$ because the $m=m^{\prime}$ drops out). We can then determine the relevant $m$ from the equation $p_{0}=r\left(p_{0}, p_{0}, m, m\right)$. 
In our numerical example, there is a consistent equilibrium with $p_{0}=1.17$, so that there is a $17 \%$ quarterly inflation rate in the pessimistic equilibrium with optimal discretionary policy. The associated value of $\mathrm{m} / \mathrm{m}^{*}$ is 1.0295 . This value is larger than the one used to construct Figure 3, as it should be: a higher level of $m$ is necessary to produce a tangency equilibrium in the pessimistic case.

There are thus two steady-state equilibria with discretionary optimal monetary policy in our quantitative example, one with low inflation and one with high inflation. The levels of the inflation rates are quite different: about 2 percent (per quarter) in one case and about 17 percent in the other.

\section{$5 \quad$ Stochastic equilibria}

The generic existence of two point-in-time equilibria and two steady-state equilibria for arbitrary homogeneous policy suggests that it may be possible to construct discretionary equilibria that involve stochastic fluctuations. We now provide an example of such an equilibrium. We assume that there is an i.i.d. sunspot realized each period which selects between the two private sector equilibria: in each period, the low- $p_{0}$ outcome occurs with probability 0.6 , the high- $p_{0}$ outcome occurs with probability of 0.4 , and this is common knowledge. ${ }^{13}$

In order for its maximization problem to be well-defined, the monetary authority must have beliefs about the current and future distribution over private-sector equilibria. Above, these beliefs were degenerate. Now that they are nondegenerate, the problem is slightly more complicated. Letting $\alpha$ be the probability of the low- $p_{0}$ outcome, the monetary authority maximizes

$$
\left\{\alpha u\left(c\left(m, \underline{p_{0}}\right), l\left(m, \underline{p_{0}}\right)\right)+(1-\alpha) u\left(c\left(m, \overline{p_{0}}\right), l\left(m, \overline{p_{0}}\right)\right)\right\}+\beta v^{\prime}
$$

where $v^{\prime}$ denotes the future expected utility, which again cannot be influenced by the current monetary authority. It is important to stress that the low and high $p_{0}$ values are influenced by the sunspot probabilities, since they satisfy the equations

$$
p_{0}=\frac{1}{m^{*}}\left[\left(\frac{1}{1+\beta E \pi\left(p_{0}, p_{0}^{\prime}\right)^{\varepsilon-1}}\right) m+\left(\frac{\beta p_{0}}{1+\beta E \pi\left(p_{0}, p_{0}^{\prime}\right)^{\varepsilon-1}}\right) E\left\{\pi\left(p_{0}, p_{0}^{\prime}\right)^{\varepsilon-1} m^{\prime}\right\}\right],
$$

where expectations are taken over the distribution of the sunspot variable. For example,

$$
E \pi\left(p_{0}, p_{0}^{\prime}\right)^{\varepsilon-1}=\alpha \pi\left(p_{0}, \underline{p}_{0}\right)^{\varepsilon-1}+(1-\alpha) \pi\left(p_{0}, \bar{p}_{0}\right)^{\varepsilon-1} .
$$

\footnotetext{
${ }^{13}$ Our model does not pin down the distribution of the sunspot variable. However, some restrictions on that distribution are imposed by the requirement that every firm's profits be nonnegative in each period. For example, if $\alpha$ is 0.75 rather than 0.6 , this condition is violated in the $\bar{p}_{0}$ state, and no discretionary equilibrium exists. As in Ennis and Keister (forthcoming), it would be interesting to study whether adaptive learning schemes would further restrict the distribution of the sunspot variable.
} 
Because the sunspot is i.i.d., this expression holds for both the low and high current value of $p_{0}$. Note that uncertainty prevents us from writing (24) as the simple weighted average that we used with perfect foresight.

\subsection{Constructing Discretionary Equilibria}

We can again apply the two computational approaches described in the previous section to construct Nash equilibria. In implementing these, we assume that the monetary authority and the private sector share the same probability beliefs.

\subsection{Optimal discretionary policy}

The relevant trade-offs for the discretionary monetary authority are illustrated in Figure 5. In panel A, there is a light solid line between the objective function for the low- $p_{0}$ private-sector equilibrium (the dark solid line) and the objective function for the high- $p_{0}$ private sector equilibrium (the dashed line): this is the monetary authority's expected utility objective, which is a weighted average of the two other objectives. The monetary authority chooses an optimal action that is about 1.0202, which is more stimulative than the earlier equilibrium action (1.01, shown in Figure $4)$ that was appropriate under extreme optimism $(\alpha=1)$. But it is smaller than the equilibrium action appropriate under extreme pessimism $(\alpha=0)$.

Figure 5 also highlights that the specific values taken on by $p_{0}$ in the optimistic and pessimistic equilibrium are endogenously determined in our setup, by current monetary policy and the sunspot probabilities. By contrast, in the essentially static models of Albanesi, Chari and Christiano [2002], the values of endogenous variables are not affected by the probability structure of extrinsic uncertainty.

\subsection{Effects of sunspots}

Consider now the effects of a sunspot on equilibrium quantities. We take as the reference point the levels in the low- $p_{0}$ private-sector equilibrium, which involve a markup of about 1.11 (close to the zero inflation markup) and a normalized price that is close to one. If the economy suddenly shifts to the high- $p_{0}$ private sector equilibrium as a result of the sunspot, then firms become much more aggressive in their adjustments. With the nominal money stock fixed $\left(M_{t}=m P_{1, t-1}\right)$, there is a decline in real aggregate demand since the price level rises. Consumption and work effort accordingly fall. Alternatively, the average markup rises dramatically, increasing distortions in the economy, to bring about this set of results. Quantitatively, in Figure 5, the rise in the markup is from about 1.12 to about 1.17 , so that there is roughly a $4.5 \%$ increase in the markup. Given that markups and consumption are (inversely) related proportionately, there is a $4.5 \%$ decline in consumption and work effort. 
These outcomes are interpretable as an incident of "unexpected stagflation" arising because of shifting beliefs. It does not correspond to the more sustained shifts in beliefs that Goodfriend [1993] describes as "inflation scares", which are associated with increases in long-term expectations of inflation as reflected in market interest rates. To consider such effects, which may be important for understanding the interaction of the U.S. central bank with the real economy during the post-war period, one could introduce persistence in the probabilities of future equilibrium selection.

\section{Summary and conclusions}

We have described equilibria under discretionary monetary policy in a basic NewKeynesian model with two-period staggered price setting. The trade-off that our monetary authority faces is a familiar one. Output is inefficiently low because firms have monopoly power, which creates an incentive for the monetary authority to provide unexpected stimulus, exploiting the pre-set prices and raising output. However, when it exploits pre-set prices, the monetary authority also raises the dispersion of prices, leading to an inefficient allocation of resources. In equilibrium, the monetary authority is balancing the marginal contribution of these two effects.

While the monetary policy trade-off is familiar, the nature of equilibrium is not. Discretionary monetary policy leads to multiple equilibria. The multiplicity occurs because of complementarity in pricing behavior that is induced by the monetary authority's natural tendency to treat the level of pre-set nominal prices as a bygone. Under discretion, in each period the monetary authority moves the nominal money supply proportionately with the nominal level of pre-set prices. This feature of monetary policy means that higher prices set by firms in the current period will lead to a higher money supply (and even higher prices) in the subsequent period. Understanding this mechanism, an individual firm adjusting its price in the current period finds it optimal to raise its price in response to higher prices set by other firms. That is: there is a complementarity in pricing, which leads to multiple equilibria.

When we consider discretionary equilibria that are driven by a sunspot variable, the equilibria involve random fluctuations between different real outcomes. ${ }^{14}$ If all firms choose to raise prices by a large amount because they (rationally) believe that others are raising prices, the result is a reduction in real aggregate demand and a decline in output relative to the level that would prevail if smaller price adjustments took place. Economic volatility then, as well as high inflation, may be a cost of discretion in monetary policy.

\footnotetext{
${ }^{14}$ The distribution of the sunspot variable shifts the equilibrium, and while we do not pin down that distribution, it is an integral part of the definition of equilibrium. Thus far, we have only considered i.i.d. sunspot variations, so as to produce the simplest possible explanation of the source and nature of multiple equilibria. In future work, we plan to extend the analysis to the implications of persistent sunspots. This extension would allow us to take the model more seriously as a potential explanation for some of the volatility observed in actual macroeconomic time series.
} 


\section{References}

[1] Albanesi, Stefania, V.V. Chari and Lawrence Christiano (2002), "Expectations Traps and Monetary Policy," NBER Working Paper 8912.

[2] Barro, Robert and David B. Gordon (1983), "A Positive Theory of Monetary Policy in a Natural Rate Model," Journal of Political Economy 91, 589-610.

[3] Blanchard, Olivier J. and Nobuhiro Kiyotaki (1987), "Monopolistic Competition and the Effects of Aggregate Demand," American Economic Review 77, 647-666.

[4] Clarida, Richard, Jordi Gali and Mark Gertler (1999), "The Science of Monetary Policy: A New Keynesian Perspective," Journal of Economic Literature 37, 16611707.

[5] Cooper, Russell W. and A. Andrew John (1988), "Coordinating Coordination Failures in Keynesian Models," Quarterly Journal of Economics 103, 441-463.

[6] Dotsey, Michael and Andreas Hornstein (2003), "Should a monetary policymaker look at money?" Journal of Monetary Economics 50, 547-79.

[7] Ennis, Huberto M. and Todd Keister (forthcoming), "Government Policy and the Probability of Coordination Failures," European Economic Review.

[8] Glomm, Gerhard and B. Ravikumar (1995), "Endogenous Public Policy and Multiple Equilibria." European Journal of Political Economy 11, 653-662.

[9] Goodfriend, Marvin (1993), "Interest Rate Policy and the Inflation Scare Problem: 1979-92," Federal Reserve Bank of Richmond Economic Quarterly (Winter), pp. 1-24.

[10] Ireland, Peter (1997), "Sustainable Monetary Policies." Journal of Economic Dynamics and Control 22 (November): 87-108.

[11] Kimball, Miles S. (1995). "The Quantitative Analytics of the Basic Neomonetarist Model", Journal of Money, Credit, and Banking, 27, 1241-1277.

[12] King, Robert G. and Alexander L. Wolman (1999), "What Should the Monetary Authority Do When Prices Are Sticky?" in Monetary Policy Rules, John Taylor, ed. University of Chicago Press, 349-398

[13] Kydland, Finn E. and Edward C. Prescott (1977), "Rules Rather than Discretion: The Inconsistency of Optimal Plans," Journal of Political Economy 85, 473-492.

[14] Rotemberg, Julio J. (1987), "The New Keynesian Microfoundations," NBER Macroeconomics Annual, MIT Press: Cambridge, MA. 
[15] Wolman, Alexander L. (2001), "A Primer on Optimal Monetary Policy in Sticky Price Models," Federal Reserve Bank of Richmond Economic Quarterly 87, 2752 .

[16] Woodford, Michael, (2002) Interest and Prices, manuscript, Chapter 3. 


\section{A Appendix}

\section{A.1 Proofs}

Proof of Proposition 1. (i) The conditions which characterize a steady-state equilibrium are (20) and (21). Multiplying (20) by the denominator of (21) reveals that these conditions are equivalent to

$$
p_{0}=h\left(p_{0}\right),
$$

where

$$
h\left(p_{0}\right)=\frac{m}{m^{*}}+\beta\left(\frac{m}{m^{*}}-1\right) p_{0}^{\varepsilon}
$$

Steady-state equilibria are thus fixed points of $h()$, and fixed points of $h()$ are steadystate equilibria.

(ii) For $p_{0}>0$ the function $h()$ is strictly positive, strictly increasing, and strictly convex.

(iii) Define $\widetilde{p}_{0}$ implicitly as follows:

$$
\widetilde{p}_{0}: h^{\prime}\left(\widetilde{p}_{0}\right)=1
$$

At $\widetilde{p}_{0}, h()$ is tangent to the $45^{\circ}$ line. By differentiating $h()$, we find that

$$
\widetilde{p}_{0}=\left(\beta \varepsilon\left(\frac{m}{m^{*}}-1\right)\right)^{1 /(1-\varepsilon)}>0,
$$

and $\widetilde{p}_{0}$ is decreasing in $m$.

Convexity of $h()$ implies that if $h\left(\widetilde{p}_{0}\right)>\widetilde{p}_{0}$ then $h()$ does not have a fixed point, and if $h\left(\widetilde{p}_{0}\right)<p_{0}$ then $h()$ has two fixed points. We now need to show that for low $m$, $h\left(\widetilde{p}_{0}\right)<\widetilde{p}_{0}$, and for high $m, h\left(\widetilde{p}_{0}\right)>\widetilde{p}_{0}$. From $(27)$ and $(26), h\left(\widetilde{p}_{0}\right) \lessgtr \widetilde{p}_{0}$ is equivalent to

$$
\frac{m}{m^{*}} \lessgtr(\beta \varepsilon)^{1 /(1-\varepsilon)}((\varepsilon-1) / \varepsilon)\left(\frac{m}{m^{*}}-1\right)^{1 /(1-\varepsilon)} .
$$

It is straightforward to show from (28) that there is a unique value of $m$, call it $\widetilde{m}$ such that $h\left(\widetilde{p}_{0}\right) \lessgtr \widetilde{p}_{0}$ for $m \lessgtr \widetilde{m}$.

Proof of Proposition 2. (Sketch) From (18) and (19), point-in-time equilibrium values of $p_{0}$ are solutions to

$$
\left(m^{*}-\frac{m}{p_{0}}\right)=\beta\left(\frac{g\left(p_{0}^{\prime}\right)}{g\left(p_{0}\right)} p_{0}\right)^{\varepsilon-1}\left(m^{\prime}-m^{*}\right),
$$

for fixed $m^{\prime}>m^{*}$ and $p_{0}^{\prime}$.

(i) The left side is strictly concave and increasing; the right hand side is strictly increasing (since $\varepsilon>1$ ), and either strictly concave (if $\varepsilon<2$ ) or strictly convex (if $\varepsilon>2)$. 
(ii) $L H S \rightarrow-\infty$ as $p_{0} \rightarrow 0^{+}$, and $\lim _{p_{0} \rightarrow \infty} L H S=m^{*}$.

(iii) $R H S(0)=0$. $R H S \rightarrow \infty$ as $p_{0} \rightarrow \infty$.

(iv) Thus, this equation has either two solutions or no solutions.

(v) Can show there is a unique $m$, call it $\breve{m}$ such that $L H S$ and $R H S$ are tangent.

(iv) As $m$ increases above $\breve{m}$, solution disappears; as $m$ decreases below $\breve{m}$ two solutions emerge 


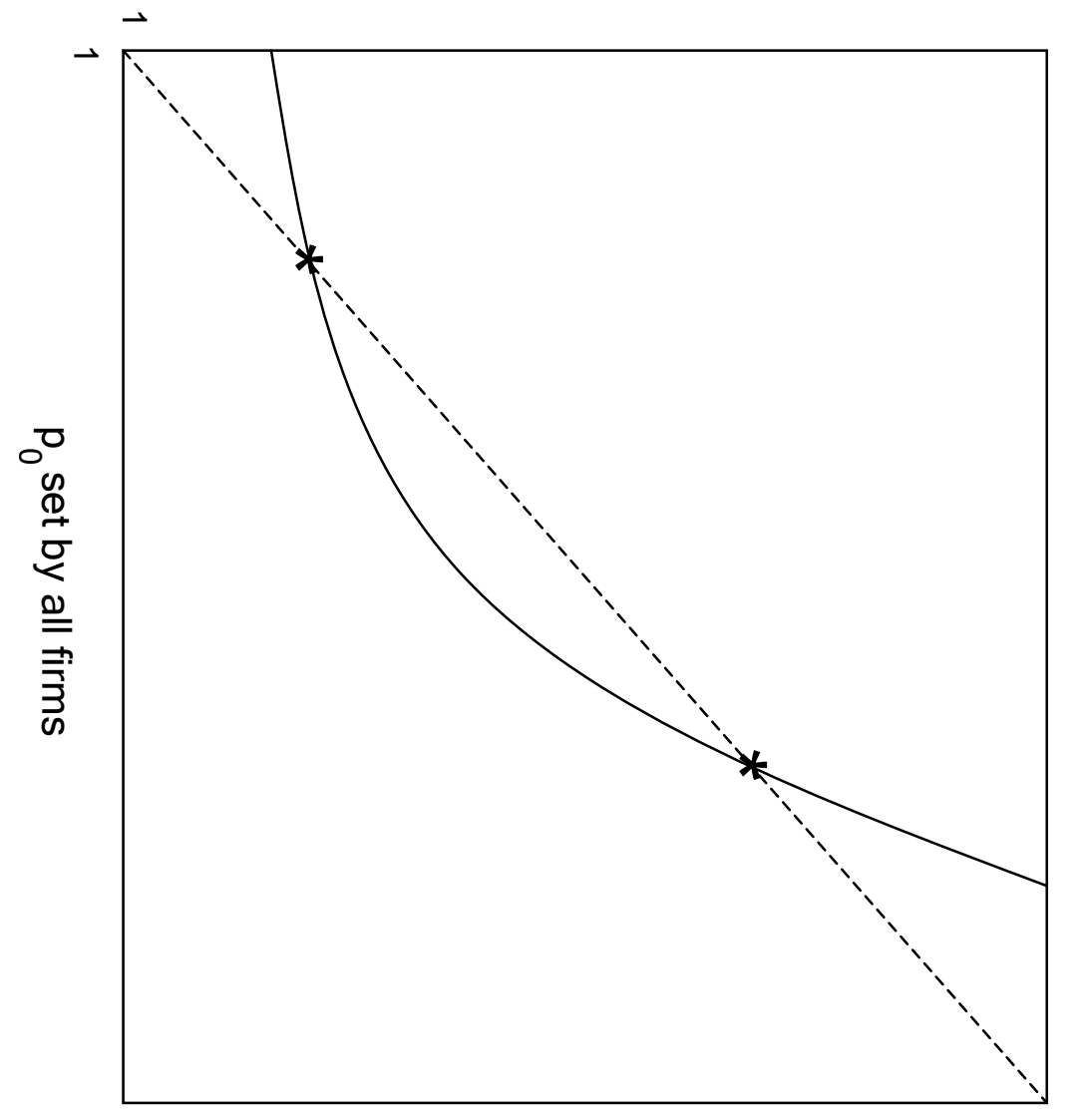

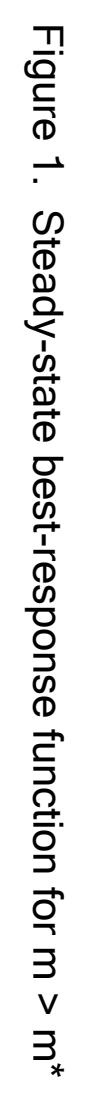




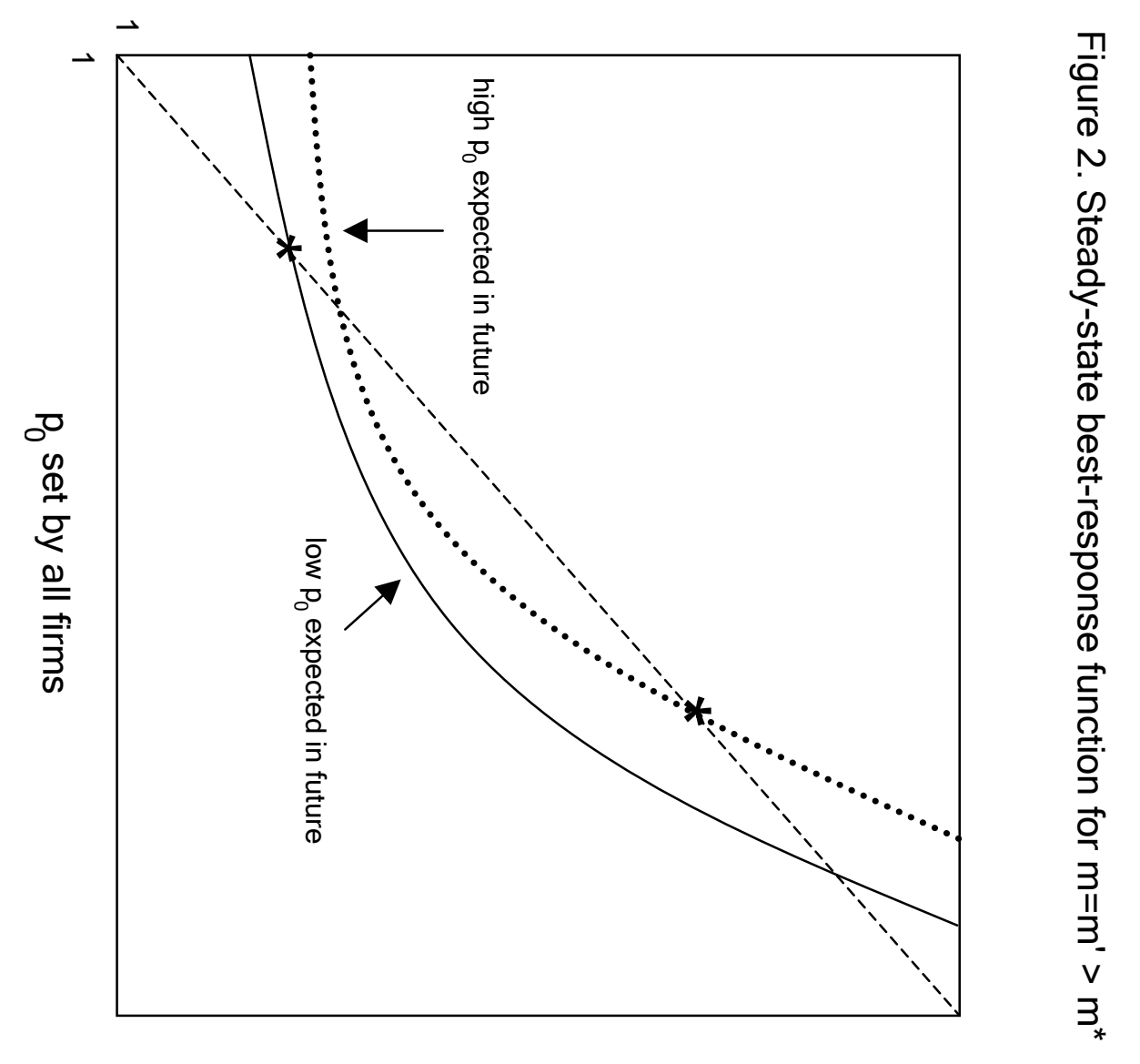


Figure 3. The temptation to stimulate a zero-inflation economy

$$
\left(\mathrm{m}^{\prime}=1.0\right)
$$

A. objective function

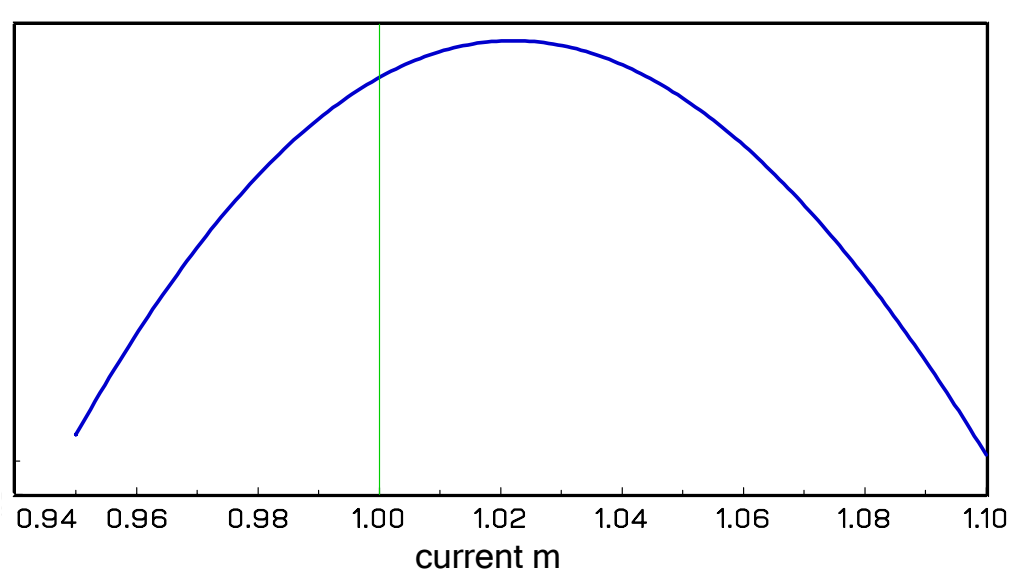

c. markup

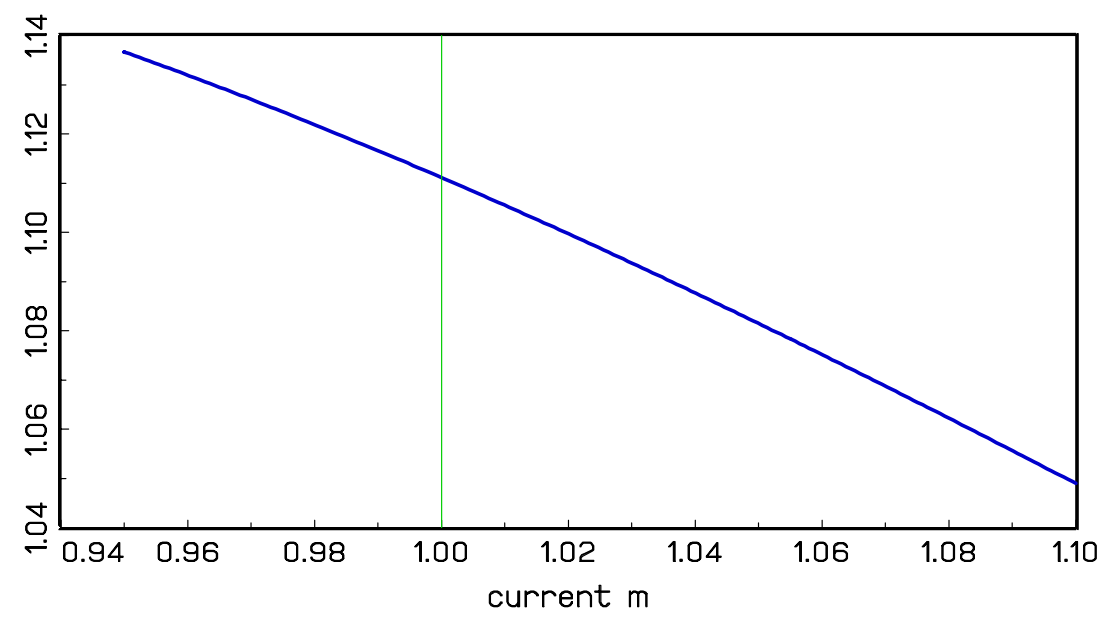

B. relative price distortion

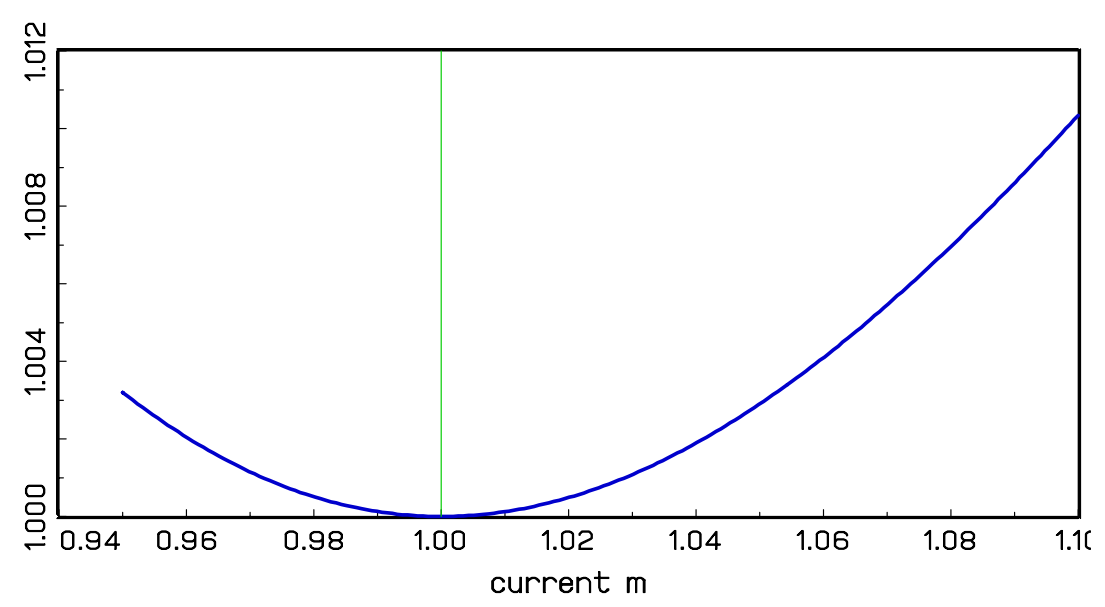

D. $p_{0}$

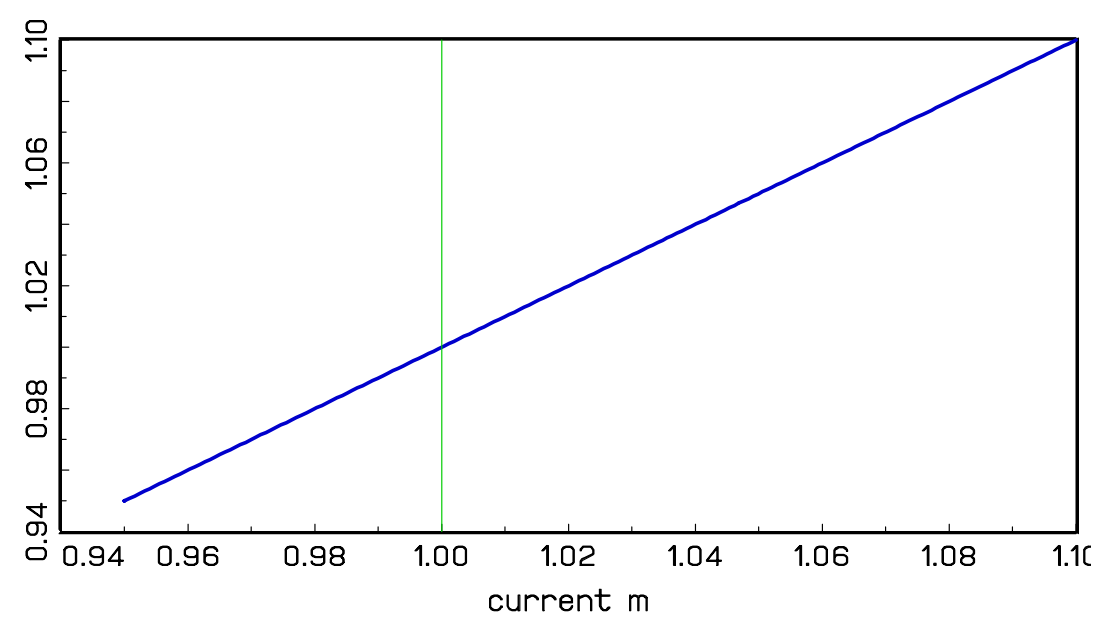


Figure 4. Discretionary equilibrium with optimism (low $\mathrm{p}_{0}$ expectations) Equilibrium $\mathrm{m}=1.010$

A. objective function

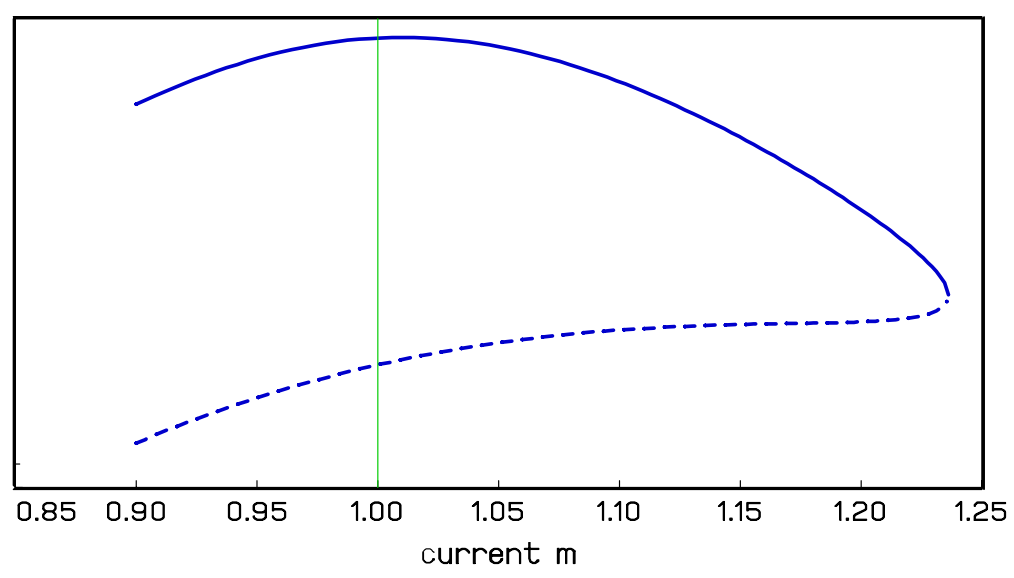

C. markup

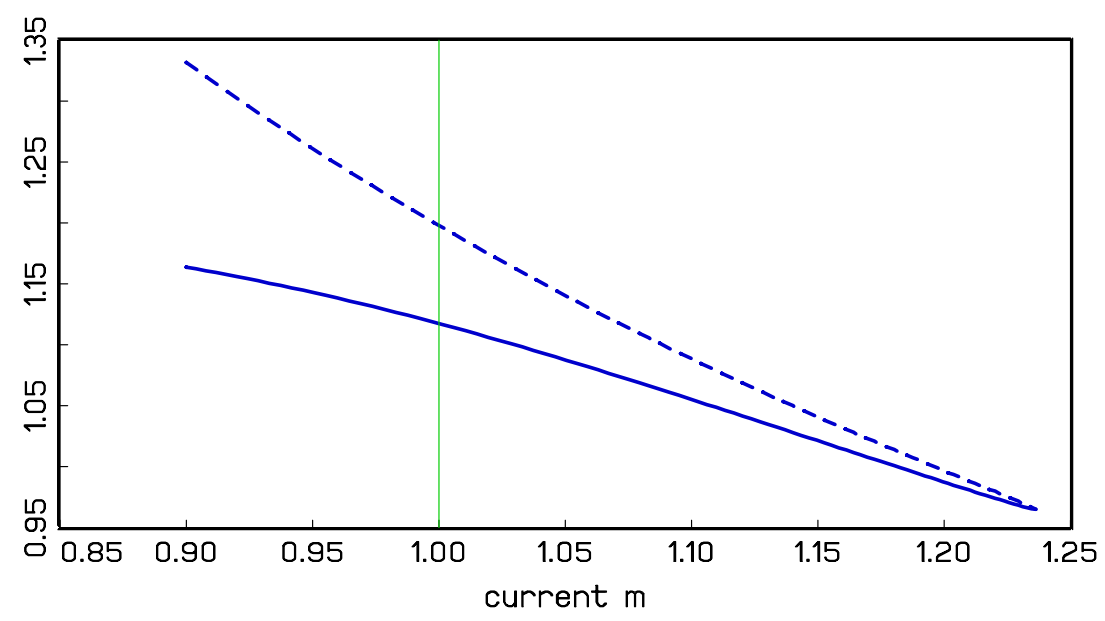

B. relative price distortion

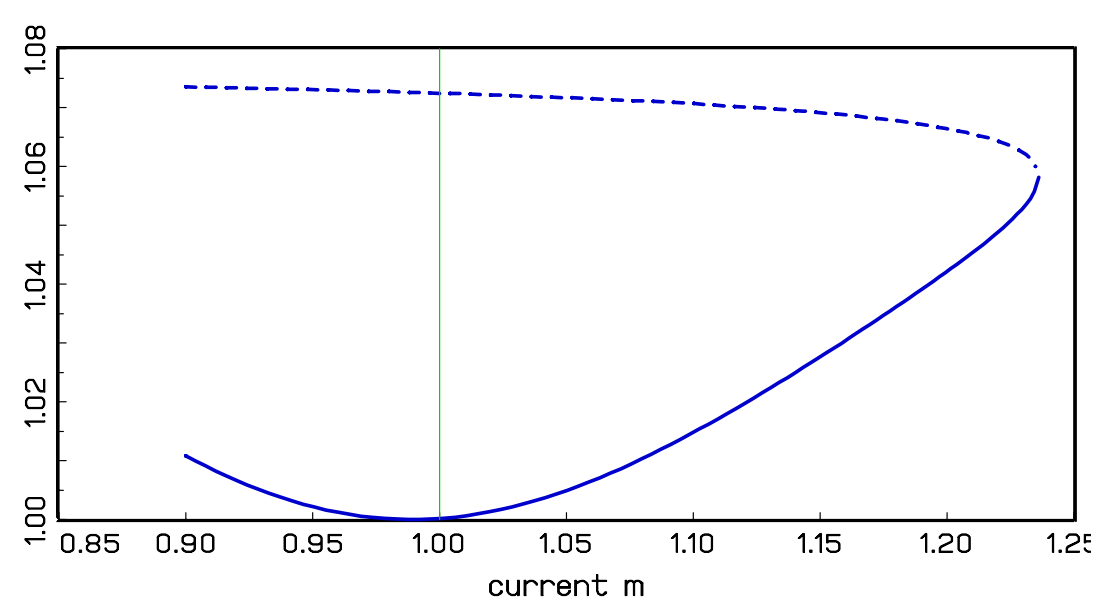

D. Po

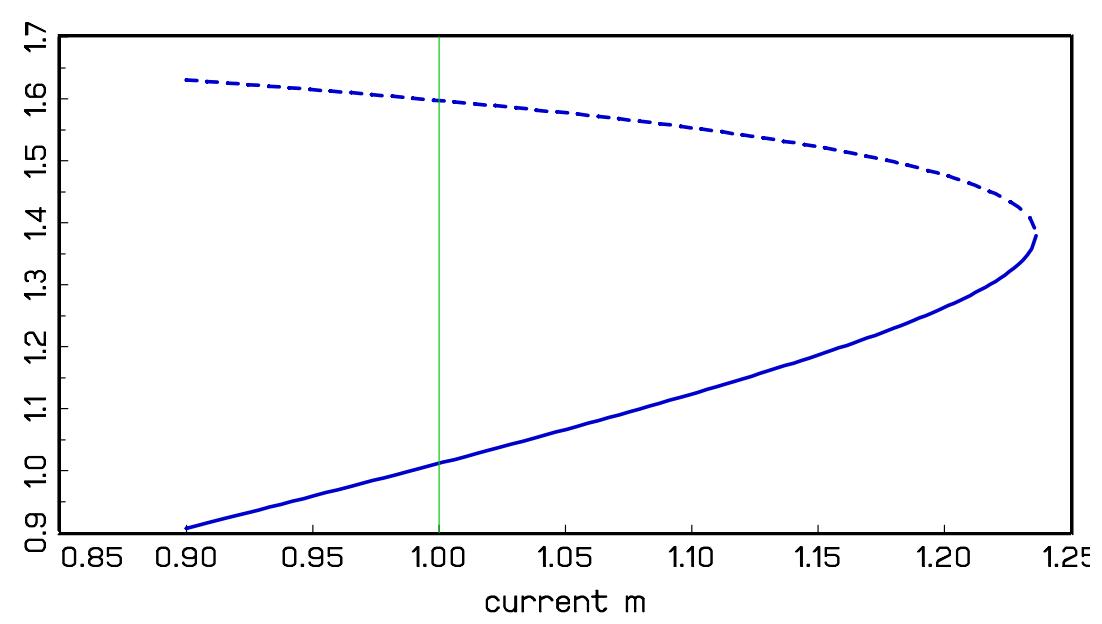


Figure 5. Discretionary equilibrium with $\operatorname{Prob}\left(\right.$ low $\left.\mathrm{p}_{0}\right)=0.6$

Equilibrium $\mathrm{m}=1.020156$

A. objective function

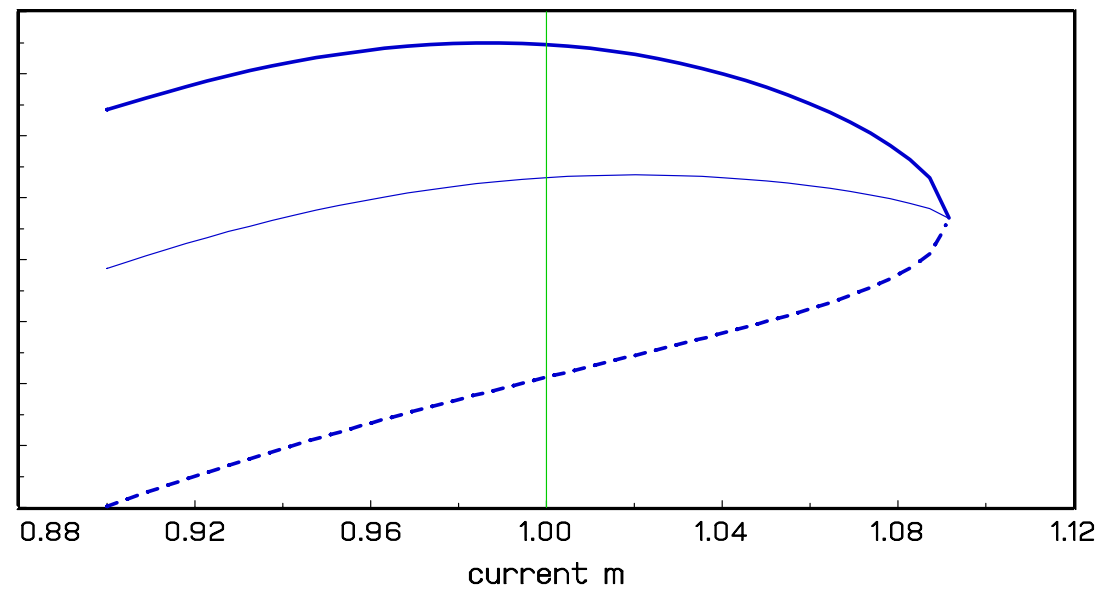

C. markup

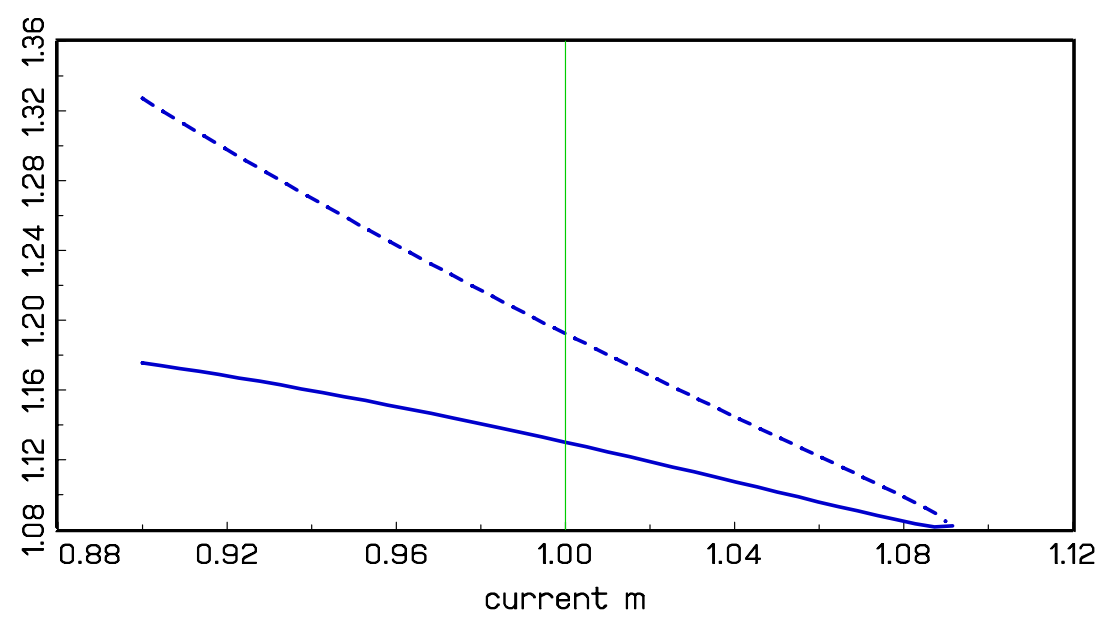

B. relative price distortion

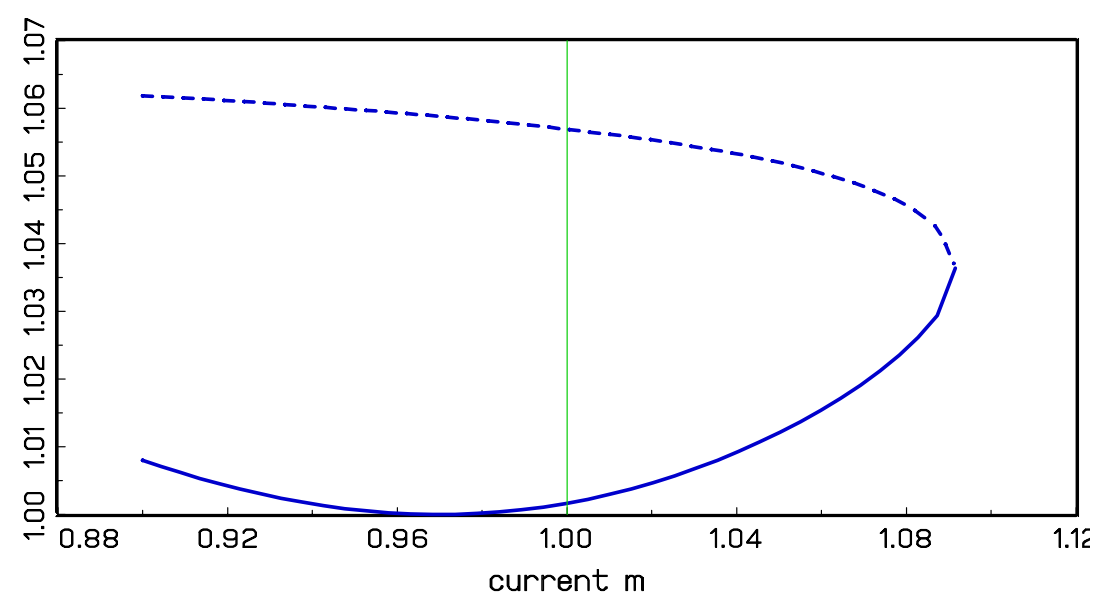

D. $p_{0}$

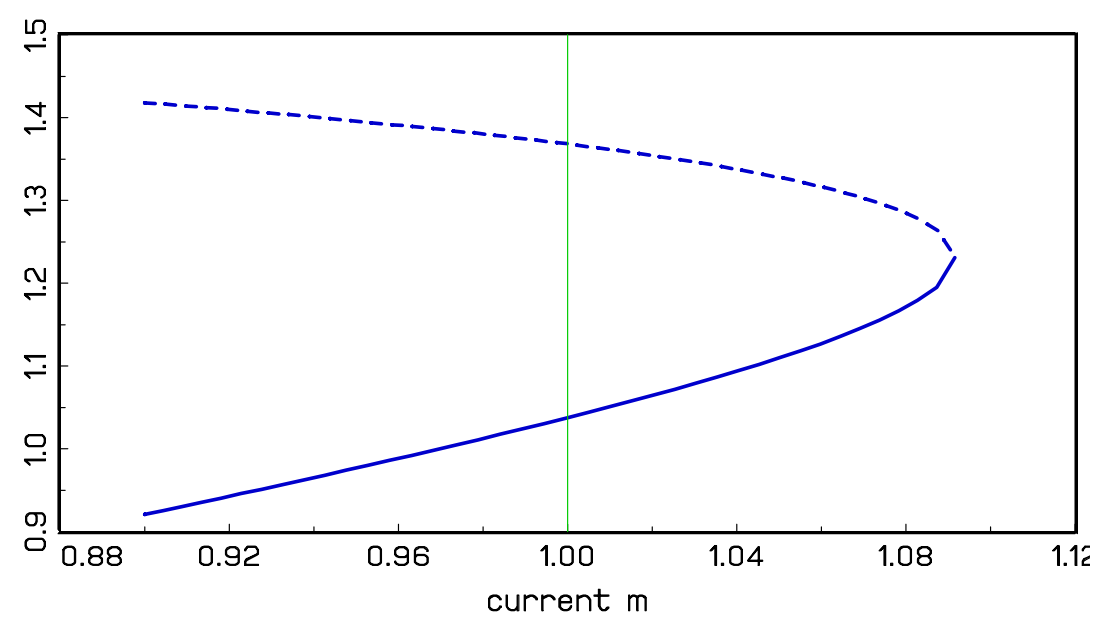

